\title{
Coupled thermo-hydro analysis of steam flow in a horizontal wellbore in a heavy oil reservoir
}

\author{
Li Mingzhong*, Wang Yiping and Wang Weiyang \\ School of Petroleum Engineering, China University of Petroleum, Qingdao, Shandong 266580, China \\ (c) China University of Petroleum (Beijing) and Springer-Verlag Berlin Heidelberg 2012
}

\begin{abstract}
A novel model for dynamic temperature distribution in heavy oil reservoirs is derived from the principle of energy conservation. A difference equation of the model is firstly separated into radial and axial difference equations and then integrated. Taking into account the coupling of temperature and pressure in the reservoir and wellbore, models for calculating distributions of the reservoir temperature, reservoir pressure, and water saturation are also developed. The steam injected into the wellbore has a more significant effect on reservoir pressure than on reservoir temperature. Calculation results indicate that the reservoir temperature and pressure decrease exponentially with increasing distance from the horizontal wellbore. The radial variation range of the pressure field induced by steam is twice as wide as that of the temperature field, and both variation ranges decrease from the wellbore heel to the toe. Variation of water saturation induced by steam is similar to the temperature and pressure fields. The radial variation ranges of the reservoir temperature and pressure increase with steam injection time, but rate of increase diminishes gradually.
\end{abstract}

Key words: Steam injection, horizontal well, dynamic temperature field, thermo-hydro coupling model, temperature profile, pressure profile

\section{Introduction}

Heavy oil reservoirs are common worldwide. Most of the heavy oil contains a significant amount of asphaltenes and the presence of asphaltene is the main reason for the high freezing point and viscosity of heavy oil. Therefore, thermal recovery methods have been widely used as the primary means of heavy oil production. Injecting steam into horizontal wells is an important thermal recovery method. Steam flow in a horizontal wellbore and in the reservoir are coupled. Steam distribution parameters can be calculated accurately by considering the coupling processes, but previous studies have mostly concentrated on pressure coupling or temperature coupling separately because of the complexity of coupling problem. Steady state reservoir/ wellbore pressure coupling was studied without considering changes of the reservoir temperature (Zhou and Guo, 2009). Exploratory research into reservoir/wellbore pressure coupling not in a steady state has been conducted (Ouyang and Azizk, 2001; Bahonar et al, 2009). A mathematical model for fluid flow in reservoirs was established with consideration of variable mass flow in the wellbore (Huang et al, 2010). Research into temperature coupling was theoretically and numerically investigated. Reservoir and wellbore temperature distribution models were studied (Hasan et al, 2007; Liu et al, 2007). Methods of establishing steady state temperature

*Corresponding author. email: limzh@upc.edu.cn

Received December 2, 2011 coupled models were studied (Livescu et al, 2008a; 2008b), and solution procedures were mentioned (Sun et al, 2010). High-accuracy models were obtained by correcting porosity variation caused by temperature (Walters et al, 2002). Some researchers studied coupled non-steady state reservoir/ wellbore temperature models (Izgec et al, 2006). However, all the above temperature models ignored changes of reservoir pressure. Several researchers did some numerical simulations (Yin et al, 2010; Zandi et al, 2010a; 2010b), and coupled numerical models for steam flow in wellbore and reservoir were obtained ( $\mathrm{Wu}$ et al, 2004). The numerical models considered the coupling of temperature and pressure, but the temperature distribution in the model was static.

In this paper, a dynamic reservoir temperature model is deduced according to energy conservation. The model is solved through difference processing. A block-centered grid system is applied to the entire reservoir domain. Axial and radial difference equations are built separately at first, and then are integrated. Models for the reservoir temperature profile, reservoir pressure profile and water saturation distribution are all developed by consideration of coupling of reservoir/wellbore temperature and pressure. Solution procedures for the coupled model are given, and calculation results of the coupled model are analyzed.

\section{Physical model}

It is a heat and mass transfer process when steam is injected into a reservoir from a horizontal wellbore (Wang, 
1994; Chen, 1996). Steam flows into the reservoir through perforations and forms a hot zone, as shown in Fig. 1. The physical model is a two-dimensional axially symmetric model for a thermal drive. The following assumptions are made for the purpose of simplification: 1) The steam injected into the reservoir flows along the radial direction; 2) The fluid flow in the reservoir obeys Darcy's law; 3) The physical properties of rocks and fluids (except the oil viscosity) do not change with temperature; 4) The temperature of the reservoir outside the hot zone remains constant.

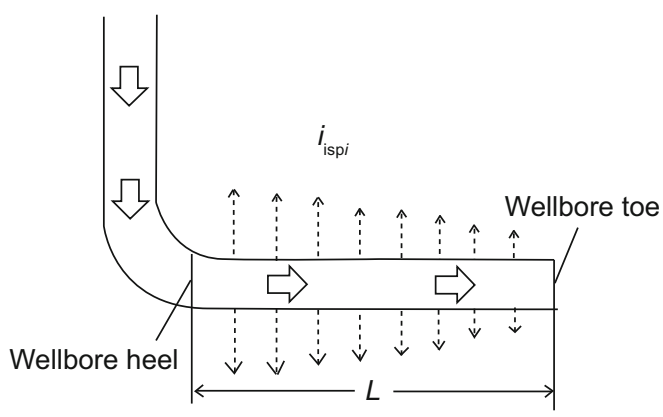

Fig. 1 Physical model of the horizontal wellbore for steam stimulation

\section{Mathematic formulations}

\subsection{Dynamic temperature distribution in the reservoir}

A micro-unit is first defined in the reservoir. The energy increment of the micro-unit includes three parts: the heat flowing into the micro-unit, the heat flowing out of the microunit and the heat injected into the micro-unit from the outside.

Energy conservation can be expressed as follows:

$$
\frac{1}{r} \frac{\partial}{\partial r}\left(\lambda_{\mathrm{e}} \cdot r \cdot \frac{\partial T}{\partial r}\right)+\frac{\partial}{\partial x}\left(\lambda_{\mathrm{e}} \cdot \frac{\partial T}{\partial x}\right)=\frac{\partial\left(\rho_{\mathrm{e}} c_{\mathrm{pe}} T\right)}{\partial \tau}
$$

where $r$ is the radius of the micro-unit, $\mathrm{m} ; x$ is the length of the micro-unit, $\mathrm{m} ; \lambda_{\mathrm{e}}$ is the effective thermal conductivity, $\mathrm{W} /$ $\left(\mathrm{m} \cdot{ }^{\circ} \mathrm{C}\right) ; T$ is temperature, ${ }^{\circ} \mathrm{C} ; r_{\mathrm{e}}$ is the effective density, $\mathrm{kg} / \mathrm{m}^{3}$; $c_{\text {pe }}$ is the effective heat capacity, $\mathrm{kJ} /\left(\mathrm{m}^{3} \cdot{ }^{\circ} \mathrm{C}\right) ; t$ is time, $\mathrm{s}$.

The product of the effective density and the effective heat capacity of the hot zone is given by:

$$
\rho_{\mathrm{e}} c_{\mathrm{pe}}=(1-\phi) \rho_{\mathrm{s}} c_{\mathrm{ps}}+\phi S_{\mathrm{o}} \rho_{\mathrm{o}} c_{\mathrm{po}}+\phi S_{\mathrm{w}} \rho_{\mathrm{w}} c_{\mathrm{pw}}
$$

According to the assumptions mentioned above, $\phi, \rho_{\mathrm{s}}$, $\rho_{\mathrm{o}}, \rho_{\mathrm{w}}, c_{\mathrm{ps}}, c_{\mathrm{po}}$, and $c_{\mathrm{pw}}$ in Eq. (2) are all independent of time. Based on the mass conservation equation, $\phi S_{1} r_{1}$ (1 represents o, w) in Eq. (2) can be expressed as a function of pressure $P$ :

$$
\begin{array}{r}
\frac{\partial\left(\phi \rho_{\mathrm{o}} S_{\mathrm{o}}\right)}{\partial \tau}=\frac{1}{r} \frac{\partial}{\partial r}\left(\frac{\rho_{\mathrm{o}} k k_{\mathrm{ro}}}{\mu_{\mathrm{o}}} \cdot r \cdot \frac{\partial P}{\partial r}\right)+\frac{\partial}{\partial x}\left(\frac{\rho_{\mathrm{o}} k k_{\mathrm{ro}}}{\mu_{\mathrm{o}}} \frac{\partial P}{\partial x}\right) \\
\frac{\partial\left(\phi \rho_{\mathrm{w}} S_{\mathrm{w}}\right)}{\partial \tau}=\frac{1}{r} \frac{\partial}{\partial r}\left(\frac{\rho_{\mathrm{w}} k k_{\mathrm{rw}}}{\mu_{\mathrm{w}}} \cdot r \cdot \frac{\partial P}{\partial r}\right)+\frac{\partial}{\partial x}\left(\frac{\rho_{\mathrm{w}} k k_{\mathrm{rw}}}{\mu_{\mathrm{w}}} \frac{\partial P}{\partial x}\right)
\end{array}
$$

Substituting Eqs. (2)-(4) into Eq. (1) gives:

$$
\begin{aligned}
& \frac{1}{r} \frac{\partial}{\partial r}\left(\lambda_{\mathrm{e}} \cdot r \cdot \frac{\partial T}{\partial r}\right)-c_{\mathrm{po}} T \frac{1}{r} \frac{\partial}{\partial r}\left(\frac{\rho_{\mathrm{o}} k k_{\mathrm{ro}}}{\mu_{\mathrm{o}}} r \frac{\partial P}{\partial r}\right)- \\
& c_{\mathrm{pw}} T \frac{1}{r} \frac{\partial}{\partial r}\left(\frac{\rho_{\mathrm{w}} k k_{\mathrm{rw}}}{\mu_{\mathrm{w}}} r \frac{\partial P}{\partial r}\right)+\frac{\partial}{\partial x}\left(\lambda_{\mathrm{e}} \cdot \frac{\partial T}{\partial x}\right)- \\
& c_{\mathrm{po}} T \frac{\partial}{\partial x}\left(\frac{\rho_{\mathrm{o}} k k_{\mathrm{ro}}}{\mu_{\mathrm{o}}} \frac{\partial P}{\partial x}\right)-c_{\mathrm{pw}} T \frac{\partial}{\partial x}\left(\frac{\rho_{\mathrm{w}} k k_{\mathrm{rw}}}{\mu_{\mathrm{w}}} \frac{\partial P}{\partial x}\right)=\rho_{\mathrm{e}} c_{\mathrm{pe}} \frac{\partial T}{\partial \tau}
\end{aligned}
$$

Eq. (5) is an energy balance equation for reservoirs in two-dimensional cylindrical coordinates. The dynamic temperature field within the reservoir can be obtained by solving Eq. (5).

Eq. (5) can be solved with difference processing. A blockcentered grid system is applied to the entire reservoir domain. Axial and radial difference equations are built separately, and then are integrated. The axial numbering is defined as $i$ and the radial numbering is defined as $j$. An equal-step difference method is used. The axial step length is $\Delta x$ and the radial step length is $\Delta r$.

The first term on the left-hand side of Eq. (5) through radial difference processing can be expressed as follows:

$$
\begin{aligned}
& \frac{1}{r} \frac{\partial}{\partial r}\left(\lambda_{\mathrm{e}} \cdot r \cdot \frac{\partial T}{\partial r}\right) \\
& =\frac{1}{r(j) \Delta r}\left[\lambda_{\mathrm{e}}\left(j+\frac{1}{2}\right) \cdot r\left(j+\frac{1}{2}\right) \cdot\left(\frac{T(j+1)-T(j)}{\Delta r}\right)\right. \\
& \left.-\lambda_{\mathrm{e}}\left(j-\frac{1}{2}\right) \cdot r\left(j-\frac{1}{2}\right) \cdot\left(\frac{T(j)-T(j-1)}{\Delta r}\right)\right]
\end{aligned}
$$

The second term on the left-hand side of Eq. (5) through radial difference processing can be expressed as follows:

$$
\begin{aligned}
& c_{\mathrm{po}} T \frac{1}{r} \frac{\partial}{\partial r}\left(\rho_{\mathrm{o}} \omega_{\mathrm{o}} r \cdot \frac{\partial P}{\partial r}\right)=\frac{c_{\mathrm{po}}(j) T(j)}{r(j) \Delta r} \times \\
& {\left[\rho_{\mathrm{o}}\left(j+\frac{1}{2}\right) \cdot \omega_{\mathrm{o}}\left(j+\frac{1}{2}\right) \cdot r\left(j+\frac{1}{2}\right) \cdot\left(\frac{P(j+1)-P(j)}{\Delta r}\right)\right.} \\
& \left.-\rho_{\mathrm{o}}\left(j-\frac{1}{2}\right) \cdot \omega_{\mathrm{o}}\left(j-\frac{1}{2}\right) \cdot r\left(j-\frac{1}{2}\right) \cdot\left(\frac{P(j)-P(j-1)}{\Delta r}\right)\right]
\end{aligned}
$$

The third term on the left-hand side of Eq. (5) through radial difference processing can be expressed as follows:

$$
\begin{aligned}
& c_{\mathrm{pw}} T \frac{1}{r} \frac{\partial}{\partial r}\left(\rho_{\mathrm{w}} \omega_{\mathrm{w}} r \cdot \frac{\partial P}{\partial r}\right)=\frac{c_{\mathrm{pw}}(j) T(j)}{r(j) \Delta r} \times \\
& {\left[\rho_{\mathrm{w}}\left(j+\frac{1}{2}\right) \cdot \omega_{\mathrm{w}}\left(j+\frac{1}{2}\right) \cdot r\left(j+\frac{1}{2}\right) \cdot\left(\frac{P(j+1)-P(j)}{\Delta r}\right)\right.} \\
& \left.-\rho_{\mathrm{w}}\left(j-\frac{1}{2}\right) \cdot \omega_{\mathrm{w}}\left(j-\frac{1}{2}\right) \cdot r\left(j-\frac{1}{2}\right) \cdot\left(\frac{P(j)-P(j-1)}{\Delta r}\right)\right]
\end{aligned}
$$


The fourth term on the left-hand side of Eq. (5) through axial difference processing is shown as follows:

$$
\frac{\partial}{\partial x}\left(\lambda_{\mathrm{e}} \cdot \frac{\partial T}{\partial x}\right)=\frac{1}{\Delta x}\left[\lambda_{\mathrm{e}}\left(i+\frac{1}{2}\right) \cdot\left(\frac{T(i+1)-T(i)}{\Delta x}\right)--\lambda_{\mathrm{e}}\left(i-\frac{1}{2}\right) \cdot\left(\frac{T(i)-T(i-1)}{\Delta x}\right)\right]
$$

The fifth term on the left-hand side of Eq. (5) through axial difference processing can be expressed as follows:

$$
c_{\mathrm{po}} T \frac{\partial}{\partial x}\left(\rho_{\mathrm{o}} \omega_{\mathrm{o}} \frac{\partial P}{\partial x}\right)=\frac{c_{\mathrm{po}}(i) T(i)}{\Delta x}\left[\rho_{\mathrm{o}}\left(i+\frac{1}{2}\right) \cdot \omega_{\mathrm{o}}\left(i+\frac{1}{2}\right) \cdot\left(\frac{P(i+1)-P(i)}{\Delta x}\right)-\rho_{\mathrm{o}}\left(i-\frac{1}{2}\right) \cdot \omega_{\mathrm{o}}\left(i-\frac{1}{2}\right) \cdot\left(\frac{P(i)-P(i-1)}{\Delta x}\right)\right]
$$

The sixth term on the left-hand side of Eq. (5) through axial difference processing is shown as follows:

$$
c_{\mathrm{pw}} T \frac{\partial}{\partial x}\left(\rho_{\mathrm{w}} \omega_{\mathrm{w}} \frac{\partial P}{\partial x}\right)=\frac{c_{\mathrm{pw}}(i) T(i)}{\Delta x}\left[\rho_{\mathrm{w}}\left(i+\frac{1}{2}\right) \cdot \omega_{\mathrm{w}}\left(i+\frac{1}{2}\right) \cdot\left(\frac{P(i+1)-P(i)}{\Delta x}\right)-\rho_{\mathrm{w}}\left(i-\frac{1}{2}\right) \cdot \omega_{\mathrm{w}}\left(i-\frac{1}{2}\right) \cdot\left(\frac{P(i)-P(i-1)}{\Delta x}\right)\right]
$$

The dynamic temperature field model of the reservoir through difference processing can be expressed as follows:

$$
\begin{aligned}
& T(i, j)=T_{\mathrm{S}}(i, j)+ \\
& \frac{\Delta \tau}{\rho_{\mathrm{e}}(i, j) c_{\mathrm{pe}}(i, j)}\left[A_{1} \cdot T(i, j+1)+A_{2} \cdot T(i, j-1)-\left(A_{1}+A_{2}-A_{3}+A_{4}+A_{5}-A_{6}\right) \cdot T(i, j)+A_{4} \cdot T(i+1, j)+A_{5} \cdot T(i-1, j)\right]
\end{aligned}
$$

with

$$
\begin{aligned}
& A_{1}=\frac{\lambda_{\mathrm{e}}\left(i, j+\frac{1}{2}\right) \cdot r\left(i, j+\frac{1}{2}\right)}{r(i, j)(\Delta r)^{2}}, A_{2}=\frac{\lambda_{\mathrm{e}}\left(i, j-\frac{1}{2}\right) \cdot r\left(i, j-\frac{1}{2}\right)}{r(i, j)(\Delta r)^{2}} \\
& A_{3}=\frac{k}{r(i, j)(\Delta r)^{2}}\left\{c_{\mathrm{po}}(i, j) \cdot \rho_{\mathrm{o}}\left(i, j+\frac{1}{2}\right) \cdot k_{\mathrm{ro}}\left(i, j+\frac{1}{2}\right) \cdot r\left(i, j+\frac{1}{2}\right) \cdot[P(i, j+1)-P(i, j)] / \mu_{\mathrm{o}}\left(i, j+\frac{1}{2}\right)\right. \\
& -c_{\mathrm{po}}(i, j) \cdot \rho_{\mathrm{o}}\left(i, j-\frac{1}{2}\right) \cdot k_{\mathrm{ro}}\left(i, j-\frac{1}{2}\right) \cdot r\left(i, j-\frac{1}{2}\right) \cdot[P(i, j+1)-P(i, j)] / \mu_{\mathrm{o}}\left(i, j-\frac{1}{2}\right) \\
& +c_{\mathrm{pw}}(i, j) \cdot \rho_{\mathrm{w}}\left(i, j+\frac{1}{2}\right) \cdot k_{\mathrm{rw}}\left(i, j+\frac{1}{2}\right) \cdot r\left(i, j+\frac{1}{2}\right) \cdot[P(i, j+1)-P(i, j)] / \mu_{\mathrm{w}}\left(i, j+\frac{1}{2}\right) \\
& \left.-c_{\mathrm{pw}}(i, j) \cdot \rho_{\mathrm{w}}\left(i, j-\frac{1}{2}\right) \cdot k_{\mathrm{rw}}\left(i, j-\frac{1}{2}\right) \cdot r\left(i, j-\frac{1}{2}\right) \cdot[P(i, j+1)-P(i, j)] / \mu_{\mathrm{w}}\left(i, j-\frac{1}{2}\right)\right\} \\
& A_{4}=\frac{\lambda_{\mathrm{e}}\left(i+\frac{1}{2}, j\right)}{(\Delta x)^{2}}, A_{5}=\frac{\lambda_{\mathrm{e}}\left(i-\frac{1}{2}, j\right)}{(\Delta x)^{2}} \\
& -c_{\mathrm{po}}(i, j) \cdot \rho_{\mathrm{o}}\left(i-\frac{1}{2}, j\right) \cdot k_{\mathrm{ro}}\left(i-\frac{1}{2}, j\right) \cdot[P(i+1, j)-P(i, j)] / \mu_{\mathrm{o}}\left(i-\frac{1}{2}, j\right) \\
& +c_{\mathrm{pw}}(i, j) \cdot \rho_{\mathrm{w}}\left(i+\frac{1}{2}, j\right) \cdot k_{\mathrm{rw}}\left(i+\frac{1}{2}, j\right) \cdot[P(i+1, j)-P(i, j)] / \mu_{\mathrm{w}}\left(i+\frac{1}{2}, j\right) \\
& \left.-c_{\mathrm{pw}}(i, j) \cdot \rho_{\mathrm{w}}\left(i-\frac{1}{2}, j\right) \cdot k_{\mathrm{rw}}\left(i-\frac{1}{2}, j\right) \cdot[P(i, j)-P(i-1, j)] / \mu_{\mathrm{w}}\left(i-\frac{1}{2}, j\right)\right\}
\end{aligned}
$$


In order to reduce the number of variables in Eq. (6), the effective thermal conductivity, relative permeability to oil and water are all represented as a function of water saturation.

The effective thermal conductivity can be written as:

$$
k_{\mathrm{ro}}=\left(1-S_{\mathrm{w}}\right)^{1 / 2}\left(1-S_{\mathrm{w}}^{1+1 / \lambda}\right)^{2}
$$

The relative permeability to oil and water are given as follows (Cheng et al, 2009):

$$
\begin{aligned}
& k_{\mathrm{ro}}=\left(1-S_{\mathrm{w}}\right)^{1 / 2}\left(1-S_{\mathrm{w}}^{1+1 / \lambda}\right)^{2} \\
& k_{\mathrm{rw}}=S_{\mathrm{w}}^{\frac{5}{2}+\frac{2}{\lambda}}
\end{aligned}
$$

The relationship between heavy oil viscosity and temperature is expressed as follows (Chen, 1996):

$$
\mu_{\mathrm{o}}=10^{\left(\frac{5.4}{1+0.014(T-50)}-1\right)}
$$

where $\phi$ is the reservoir porosity; $P$ is pressure, $\mathrm{MPa} ; k$ is the absolute permeability, $\mu \mathrm{m}^{2} ; \lambda$ is the pore size distribution index; $k_{\mathrm{ro}}, k_{\mathrm{rw}}$ are the relative permeability to oil and water; $S_{\mathrm{o}}, S_{\mathrm{w}}$ are the oil saturation and water saturation, respectively; $\mu_{\mathrm{o}}, \mu_{\mathrm{w}}$ are the oil viscosity and water viscosity, respectively, $\mathrm{mPa} \cdot \mathrm{s} ; \rho_{\mathrm{s}}, \rho_{\mathrm{o}}, \rho_{\mathrm{w}}$ denote the densities of rock, oil and water, $\mathrm{kg} / \mathrm{m}^{3} ; c_{\mathrm{ps}}, c_{\mathrm{po}}, c_{\mathrm{pw}}$ denote the heat capacity of rock, oil and water, $\mathrm{kJ} /\left(\mathrm{m}^{3} \cdot{ }^{\circ} \mathrm{C}\right) ; l_{\mathrm{s}}, l_{\mathrm{o}}, l_{\mathrm{w}}$ denote the thermal conductivity of rock, oil and water, $\mathrm{W} /\left(\mathrm{m} \cdot{ }^{\circ} \mathrm{C}\right) ; T_{\mathrm{s}}$ is the reservoir temperature field at the previous time units.

Set $x=0$ at the heel of the horizontal wellbore, and set $x=L$ at the toe. In the case of a perforated completion, the total number of perforations along the horizontal well is $N$. The temperature at the perforation tunnel $i$ is defined as $T_{\mathrm{w} i}$.

Let the radial serial number $j=1$, and the borehole wall temperature $T(i, 1)$ is obtained, that is $T_{\text {wi }}$. $N$ equations including $T_{\mathrm{w} i}, P_{\mathrm{w} i}, S_{\mathrm{w} i}$ are obtained from Eq. (6). The equations include $3 N$ unknown variables: $T_{\mathrm{w} i}, P_{\mathrm{w} i}, S_{\mathrm{w} i}(i=1,2,3, \cdots, N)$, and can be expressed as follows:

$$
F_{\mathrm{TF}}\left(T_{\mathrm{w} i}, P_{\mathrm{w} i}, S_{\mathrm{w} i}\right)=0
$$

Eq. (11) shows the influence of formation pressure and water saturation on the formation temperature at the borehole wall at segment $i$.

\subsection{Wellbore temperature distribution}

The wellbore is divided into $N$ segments according to the number of perforations. The model for temperature change of each segment is obtained by establishing control equations (Wang et al, 2010):

$$
\begin{aligned}
& \mathrm{d} T=-\frac{1}{i_{\text {isp }} C_{\mathrm{s}}}\left\{\mathrm{d} Q+\mathrm{d} W+\mathrm{d} i_{\text {isp }}\left(\frac{v_{\mathrm{m}}^{2}-v_{\mathrm{r}}^{2}}{2}\right)\right. \\
& \left.+i_{\text {isp }} v_{\mathrm{m}}\left[\frac{i_{\text {isp }}}{\rho_{\mathrm{m}} A_{\mathrm{h}}}\left(\frac{1}{T} \frac{d T}{d P}-\frac{1}{P}\right) \mathrm{d} P+\frac{\mathrm{d} i_{\text {isp }}}{\rho_{\mathrm{m}} A_{\mathrm{h}}}\right]\right\}
\end{aligned}
$$

where $\mathrm{d} Q$ is the heat loss per unit time, $\mathrm{kJ} / \mathrm{s} ; \mathrm{d} W$ is the work done by friction per unit time, $\mathrm{kJ} / \mathrm{s} ; i_{\text {isp }}$ is the steam absorption in the current segment, $\mathrm{kg} / \mathrm{s} ; v_{\mathrm{m}}$ is the steam flow rate in the wellbore, $\mathrm{m} / \mathrm{s} ; v_{\mathrm{r}}$ is the steam rate which flows into the formation, $\mathrm{m} / \mathrm{s} ; \rho_{\mathrm{m}}$ is the steam density in the current segment, $\mathrm{kg} / \mathrm{m}^{3} ; A_{\mathrm{h}}$ is the cross sectional area of the segment, $\mathrm{m}^{2} ; P$ is the steam injection pressure, $\mathrm{MPa} ; T$ is the steam temperature, ${ }^{\circ} \mathrm{C} ; C_{\mathrm{s}}$ is the specific heat capacity of steam, $\mathrm{kJ} /\left(\mathrm{m}^{3} \cdot{ }^{\circ} \mathrm{C}\right)$.

When the steam injection pressure and the steam absorption are known, the temperature change $\Delta T_{\mathrm{w}}$ at perforation tunnel $i$ can be obtained from Eq. (12). Substituting $\Delta T_{\mathrm{w}}$ into the following equation:

$$
\left\{\begin{array}{l}
T_{\mathrm{w} i}=T_{\mathrm{w}, i-1}-\frac{1}{2}\left(\Delta T_{\mathrm{w}, i-1}+\Delta T_{\mathrm{w} i}\right) \quad(i=1,2, \cdots, N) \\
T_{\mathrm{w} 0}=T_{\mathrm{wf}} \\
\Delta T_{\mathrm{w} 0}=0
\end{array}\right.
$$

We obtain $N$ equations including $i_{\text {ispi }}, T_{\text {wi }}, P_{\text {wi }}$ :

$$
F_{\mathrm{TW}}\left(i_{\text {ispi }}, T_{\mathrm{w} i}, P_{\mathrm{w} i}\right)=0
$$

where $T_{\mathrm{wf}}$ is the temperature of the wellbore heel, ${ }^{\circ} \mathrm{C} ; i_{\text {isp } i}$ is the steam absorption at perforation tunnel $i, \mathrm{~kg} / \mathrm{s}$.

Eq. (14) shows the influence of steam pressure and steam absorption on the steam temperature at segment $i$.

The equations include $3 N$ unknown variables: $T_{\mathrm{w} i}, P_{\mathrm{w} i}, i_{\text {isp } i}$ $(i=1,2,3, \cdots, N)$.

\subsection{Pressure distribution in the reservoir}

The mass flow of steam which is injected into the reservoir at perforation tunnel $i$ is $i_{\text {ispi }}$. The pressure at perforation tunnel $i$ is $P_{\mathrm{w} i}$. According to potential superposition principle, the seepage equation of the two-phase oil-water mixture which follows Darcy's law can be derived, and can be expressed as follows (Liu et al, 1999; Su et al, 2007):

$$
\boldsymbol{A} \boldsymbol{I}=\boldsymbol{B}
$$

with

$$
\begin{aligned}
& \boldsymbol{I}=\left[i_{\text {isp } 1}, i_{\text {isp } 2}, i_{\text {isp } 3}, \cdots, i_{\text {isp } N}\right]^{\mathrm{T}} \\
& \boldsymbol{A}=\left[\begin{array}{ccccc}
\phi_{11}-\phi_{\mathrm{e} 1} & \phi_{12}-\phi_{\mathrm{e} 2} & \phi_{13}-\phi_{\mathrm{e} 3} & \cdots & \phi_{1 N}-\phi_{\mathrm{eN}} \\
\phi_{21}-\phi_{\mathrm{e} 1} & \phi_{22}-\phi_{\mathrm{e} 2} & \phi_{23}-\phi_{\mathrm{e} 3} & \cdots & \phi_{2 N}-\phi_{\mathrm{eN}} \\
\phi_{31}-\phi_{\mathrm{e} 1} & \phi_{32}-\phi_{\mathrm{e} 2} & \phi_{33}-\phi_{\mathrm{e} 3} & \cdots & \phi_{3 N}-\phi_{\mathrm{e} N} \\
\vdots & \vdots & \vdots & \ddots & \vdots \\
\phi_{N 1}-\phi_{\mathrm{e} 1} & \phi_{N 2}-\phi_{\mathrm{e} 2} & \phi_{N 3}-\phi_{\mathrm{e} 3} & \cdots & \phi_{N N}-\phi_{\mathrm{eN}}
\end{array}\right] \\
& \boldsymbol{B}=\left[\begin{array}{c}
4 \pi L_{\mathrm{p} 1}\left(H_{\mathrm{w} 1}-H_{\mathrm{e}}\right) \\
4 \pi L_{\mathrm{p} 2}\left(H_{\mathrm{w} 2}-H_{\mathrm{e}}\right) \\
4 \pi L_{\mathrm{p} 3}\left(H_{\mathrm{w} 3}-H_{\mathrm{e}}\right) \\
\vdots \\
4 \pi L_{\mathrm{p} N}\left(H_{\mathrm{w} N}-H_{\mathrm{e}}\right)
\end{array}\right]
\end{aligned}
$$




$$
\begin{aligned}
& H_{i}=\sum_{i=1}^{N} \frac{i_{\mathrm{isp} i}}{4 \pi L_{\mathrm{p} i}} \phi_{i}+C \\
& \phi_{i}=\ln \frac{r_{i}+L_{\mathrm{p} i}}{r_{i}-L_{\mathrm{p} i}} \\
& r_{i}=\sqrt{\left(x_{i}-x\right)^{2}+\left(r_{\mathrm{w} i} \sin \theta_{i}-y\right)^{2}+\left[\left(z_{i}+r_{\mathrm{w} i} \cos \theta_{i}\right)-z\right]^{2}} \\
& +\sqrt{\left(x_{i}-x\right)^{2}+\left[\left(r_{\mathrm{w} i}+L_{\mathrm{p} i}\right) \sin \theta_{i}-y\right]^{2}} \\
& +\left[\left(z_{i}+\left(r_{\mathrm{w} i}+L_{\mathrm{p} i}\right) \cos \theta_{i}\right)-z\right]^{2}
\end{aligned}
$$

where $\boldsymbol{A}$ is the coefficient matrix associated with the calculation position; $\boldsymbol{B}$ is the matrix associated with pressure; $\boldsymbol{I}$ is the column matrix composed of the micro-unit steam absorption; $H_{\mathrm{e}}$ is the potential at the reservoir boundary; $H_{\mathrm{w} i}$ is the potential at perforation tunnel $i ; L_{\mathrm{p} i}$ is the length of perforation tunnel $i ; \phi_{j i}$ is the value of $\phi_{i}$ at segment $j ; \phi_{\mathrm{e} i}$ is the value of $\phi_{i}$ at the reservoir boundary; $C$ is the integral constant; $x_{i}$ is the abscissa of perforation tunnel $i ; z_{i}$ is the coordinate of perforation tunnel $i$ in the $z$ direction; $r_{\mathrm{w} i}$ is the radius of the horizontal wellbore at perforation tunnel $i, \mathrm{~m} ; q_{i}$ is the perforation deflection angle at perforation tunnel $i, \mathrm{rad}$; $(x, y, z)$ is the coordinates of the calculation position in the reservoir.

Pressure $P_{\mathrm{w} i}$, temperature $T_{\mathrm{w} i}$, and water saturation $S_{\mathrm{w} i}$ are all implied in the potential function $H$. Therefore Eq. (15) includes $4 N$ unknown variables: $i_{\text {isp } i}, T_{\mathrm{w} i}, P_{\mathrm{w} i}, S_{\mathrm{w} i}(i=1,2,3, \cdots$, $N)$, and can be expressed as follows:

$$
F_{\mathrm{PF}}\left(i_{\text {isp } i}, T_{\mathrm{w} i}, P_{\mathrm{w} i}, S_{\mathrm{w} i}\right)=0
$$

Eq. (16) shows the influence of formation temperature, steam absorption and water saturation on the formation pressure of the borehole wall at segment $i$.

\subsection{Wellbore pressure distribution}

A pressure drop model for the wellbore can be derived by dividing the wellbore into $N$ segments and establishing control equations (Wang et al, 2010):

$$
\mathrm{d} P=\frac{2 v_{\mathrm{m}} \mathrm{d} i_{\text {isp }}+\tau_{\mathrm{c}}}{A_{\mathrm{h}}+\left(\frac{1}{T} \frac{\mathrm{d} T}{\mathrm{~d} P}-\frac{1}{P}\right) v_{\mathrm{m}} i_{\text {isp }}}
$$

where $t_{\mathrm{c}}$ is the friction force between steam and casing, $\mathrm{N}$.

When the steam temperature and steam absorption are known, the pressure change $\Delta P_{\mathrm{w} i}$ at perforation tunnel $i$ can be obtained from Eq. (17). Substituting the pressure $P_{\text {wf }}$ at the wellbore heel and pressure change $\Delta P_{\mathrm{w} i}$ into Eq. (18), we can obtain the pressure distribution in the horizontal wellbore:

$$
\left\{\begin{array}{l}
P_{\mathrm{w} i}=P_{\mathrm{w}, i-1}-\frac{1}{2}\left(\Delta P_{\mathrm{w}, i-1}+\Delta P_{\mathrm{w} i}\right) \quad(i=1,2, \cdots, N) \\
P_{\mathrm{w} 0}=P_{\mathrm{wf}} \\
\Delta P_{\mathrm{w} 0}=0
\end{array}\right.
$$

Set the steam absorption, pressure and temperature as an $\mathrm{N}$-dimensional vector, and then the equation includes $3 \mathrm{~N}$ unknown variables and can be expressed as follows:

$$
F_{\mathrm{PW}}\left(i_{\text {ispi }}, P_{\mathrm{w} i}, T_{\mathrm{w} i}\right)=0
$$

Eq. (19) shows the influence of steam temperature and absorption on the steam pressure at segment $i$.

\subsection{Coupled thermo-hydro model}

Based on the coupling relationship between temperature continuity and pressure continuity, both the reservoir temperature and wellbore temperature and the reservoir pressure and wellbore pressure are the same at the borehole wall. A model for thermo-hydro coupling in the reservoir and horizontal wellbore can be obtained by combining reservoir temperature Eq. (11), wellbore temperature Eq. (14), reservoir pressure Eq. (16) and wellbore pressure Eq. (19). Unknown variables in the coupled model include $i_{\text {ispi } i}, P_{\mathrm{w} i}, T_{\mathrm{w} i}$, and $S_{\mathrm{w} i}$, whose number is $4 N$, equaling the number of equations. Therefore, the coupled model has a unique solution.

The boundary and initial conditions of the coupled model are listed below:

$$
\left\{\begin{array}{l}
r=r_{\mathrm{w}}, \quad P=P_{\mathrm{w}}, \quad T=T_{\mathrm{w}} \\
r=r_{\infty}, \quad P=P_{\mathrm{e}}, \quad T=T_{\mathrm{e}} \\
r_{\mathrm{w}} \leq r \leq r_{\infty} \\
S_{\mathrm{w}}+S_{\mathrm{o}}=1
\end{array}\right.
$$

where $P_{\mathrm{w}}$ is the wellbore pressure, $\mathrm{MPa} ; T_{\mathrm{w}}$ is the wellbore temperature, ${ }^{\circ} \mathrm{C} ; P_{\mathrm{e}}$ is the initial reservoir pressure, $\mathrm{MPa} ; T_{\mathrm{e}}$ is the initial reservoir temperature, ${ }^{\circ} \mathrm{C}$.

\section{Solution procedures for the coupled model}

Since the equation coefficients are functions of unknown parameters, the coupled model is a complex nonlinear equation system, which should be solved by an iterative method. As can be seen from the coupled model, in each timing-cycle, the temperature influences the fluid viscosity, and then the pressure distribution in the flow region. In the solution process, the temperature field is first determined, and the pressure is subsequently obtained. Solution procedures for the coupled model are as follows:

1) In a time step $\Delta t$, temperature $T_{\mathrm{w} i}$ and water saturation $S_{\mathrm{w} i}$ are initialized;

2) According to the three-dimensional coordinates of the horizontal wellbore, $\phi_{j i}$ in Eq. (15) can be calculated, and then matrix $\boldsymbol{A}$ can be obtained; 
3) Set initial value of $P_{\mathrm{w} i} \cdot P_{\mathrm{w} i}=P_{\mathrm{wf}}$ can be assumed before calculation;

4) Calculate the potential function $H_{\mathrm{wi}}$ in Eq. (15), and then calculate matrix $\boldsymbol{B}$;

5) Solve Eq. (15) using the Gaussian elimination method, and then obtain $i_{\text {isp } i}$;

6) Substitute $i_{\text {ispi }}$ obtained by Step (5) into the wellbore pressure model, update $P_{\mathrm{w} i}$ and record as $P_{\text {wi }}^{\prime}$;

7) With pre-given $\varepsilon_{\mathrm{p}}$, if $\max \left|P_{\mathrm{w} i}^{\prime}-P_{\mathrm{w} i}\right|<\varepsilon_{\mathrm{p}}$, let $P_{\mathrm{w} i}=P_{\mathrm{w} i}^{\prime}$, and go to next step. If $P^{\prime}{ }_{\text {wi }}$ cannot meet the accuracy requirement, let $P^{\prime}{ }_{\text {wi }}$ be the supposed value in Step (3), and repeat Step (4) to Step (7);

8) Substitute the calculated values $i_{\text {ispi }}$ and $P_{\text {wi }}$ into the wellbore temperature equation, and calculate the temperature distribution $T_{\mathrm{w} i}$ in the wellbore;

9) Substitute $P_{\mathrm{w} i}$ and $T_{\mathrm{w} i}$ into Eq. (6), and calculate the water saturation distribution $S_{\mathrm{w} i}$ at current time;

10) With pre-given $\varepsilon_{\mathrm{T}}$ and $\varepsilon_{\mathrm{S}}$, if $\max \left|T^{\prime}{ }_{\mathrm{w} i}-T_{\mathrm{w} i}\right|<\varepsilon_{\mathrm{T}}$ and $\max \left|S^{\prime}{ }_{\mathrm{w} i}-S_{\mathrm{w} i}\right|<\varepsilon_{\mathrm{S}}$, let $T_{\mathrm{w} i}=T^{\prime}{ }_{\mathrm{w} i}$ and $S_{\mathrm{w} i}=S^{\prime}{ }_{\mathrm{w} i}$, stop iteration. If $T_{\mathrm{w} i}$ or $S^{\prime}{ }_{\mathrm{w} i}$ cannot meet the accuracy requirements, let $S^{\prime}{ }_{\mathrm{w} i}$ and $S^{\prime}{ }_{w i}$ be the supposed values in Step (1), and repeat Step (2) to Step (10);

11) Compare $\tau$ with $t_{\max }$. If $\tau<\tau_{\max }$, let $\tau=\tau+\Delta \tau$ and go to Step (1), else end the calculation.

\section{Calculation example}

A horizontal well in a heavy oil reservoir is taken as an example. Basic data of the reservoir and the horizontal well are listed in Table 1.

Table 1 Basic data for the example

\begin{tabular}{|c|c|c|}
\hline \multirow{11}{*}{$\begin{array}{l}\text { Reservoir } \\
\text { parameters }\end{array}$} & Depth, m & 750 \\
\hline & Thickness, $\mathrm{m}$ & 12 \\
\hline & Original temperature, ${ }^{\circ} \mathrm{C}$ & 48.5 \\
\hline & Original pressure, $\mathrm{MPa}$ & 7.5 \\
\hline & Porosity, $\%$ & 31.2 \\
\hline & Permeability, $\mu \mathrm{m}^{2}$ & 12 \\
\hline & Original oil saturation, $\%$ & 60 \\
\hline & Original water saturation, $\%$ & 40 \\
\hline & Pore size distribution index & 4 \\
\hline & Heat capacity, $\mathrm{kJ} /\left(\mathrm{m}^{3} \cdot{ }^{\circ} \mathrm{C}\right)$ & $2.0 \times 10^{3}$ \\
\hline & Thermal conductivity, $\mathrm{W} /\left(\mathrm{m} \cdot{ }^{\circ} \mathrm{C}\right)$ & 1.72 \\
\hline \multirow{2}{*}{$\begin{array}{c}\text { Wellbore } \\
\text { parameters }\end{array}$} & Wellbore diameter, $\mathrm{mm}$ & 159.4 \\
\hline & Horizontal section length, $\mathrm{m}$ & 200 \\
\hline \multirow{3}{*}{$\begin{array}{l}\text { Heavy oil } \\
\text { parameters }\end{array}$} & Heat capacity, $\mathrm{kJ} /\left(\mathrm{m}^{3} \cdot{ }^{\circ} \mathrm{C}\right)$ & $2.1 \times 10^{3}$ \\
\hline & Thermal conductivity, $\mathrm{W} /\left(\mathrm{m} \cdot{ }^{\circ} \mathrm{C}\right)$ & 1.35 \\
\hline & Viscosity at $50^{\circ} \mathrm{C}, \mathrm{mPa} \cdot \mathrm{s}$ & $3.4 \times 10^{4}$ \\
\hline \multirow{4}{*}{$\begin{array}{c}\text { Steam } \\
\text { parameters }\end{array}$} & Temperature at the wellbore heel, ${ }^{\circ} \mathrm{C}$ & 337 \\
\hline & Pressure at the wellbore heel, MPa & 14.1 \\
\hline & Dryness at the wellbore heel, $\%$ & 56 \\
\hline & Injection rate, $\mathrm{t} / \mathrm{h}$ & 9 \\
\hline
\end{tabular}

During the calculation process, the time step is $1 \mathrm{~h}$, the radial step is $1 \mathrm{~cm}$, and the horizontal step is $1 \mathrm{~m}$. When $\tau=96 \mathrm{~h}$, the distribution of steam absorption along the horizontal wellbore is shown in Fig. 2. Distributions of the reservoir temperature, reservoir pressure and water saturation along the radial direction are shown in Figs. 3-5. When $\tau=1$, $2,4,6,8$ and $10 \mathrm{~d}$, the variations of reservoir temperature and pressure at the position of $x=60 \mathrm{~m}$ are shown in Figs. 6 and 7, respectively.

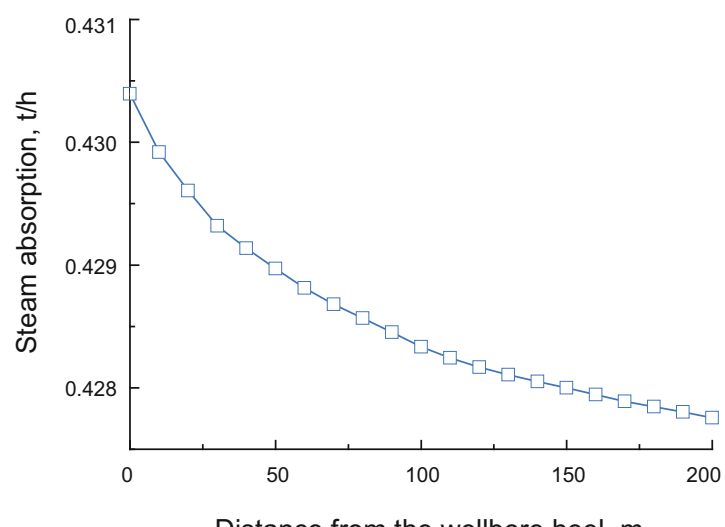

Distance from the wellbore heel, $\mathrm{m}$

Fig. 2 Steam absorption along the horizontal wellbore

Fig. 2 indicates that steam absorption decreases gradually along the horizontal direction. This is because the wellbore pressure decreases from heel to toe (Wang et al, 2010b), and the pressure difference between reservoir and wellbore becomes smaller, resulting in a reduction in steam absorption ability.

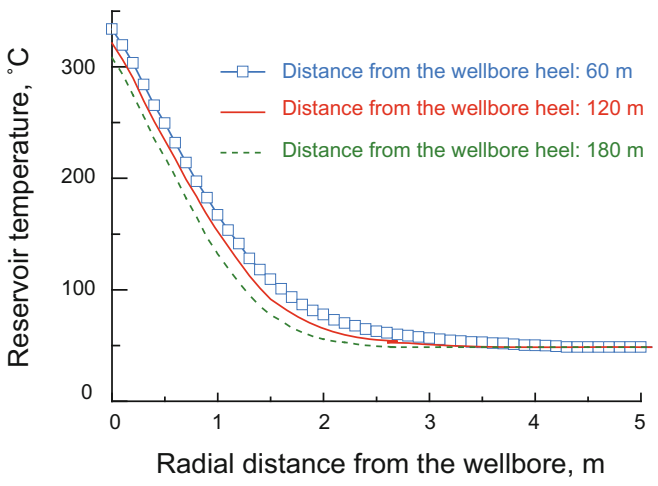

Fig. 3 Radial distribution curves of the reservoir temperature

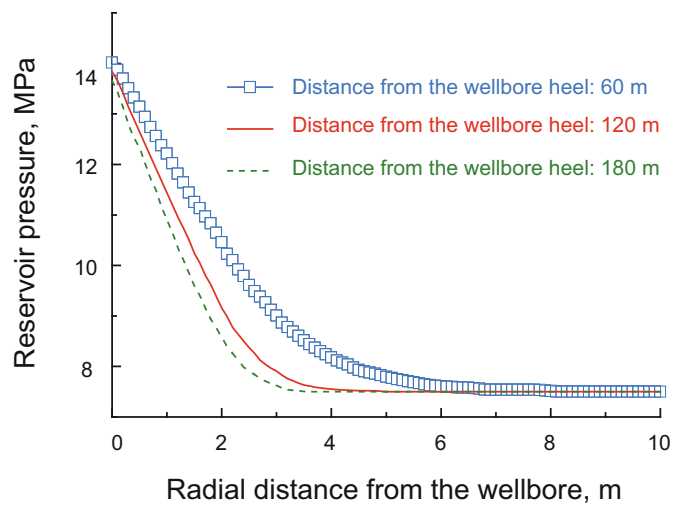

Fig. 4 Radial distribution curves of the reservoir pressure 


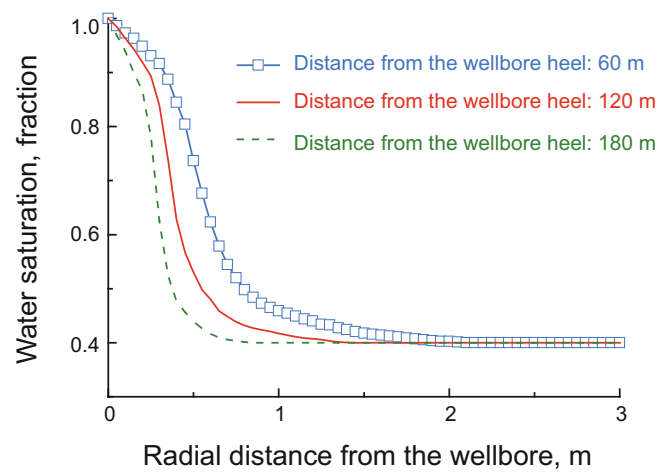

Fig. 5 Radial distribution curves of the water saturation

The distributions of the reservoir temperature and pressure in the radial direction (illustrated in Figs. 3 and 4) indicate that only a small zone near the horizontal wellbore is swept by steam. Maximum values of the reservoir temperature and pressure appear at the borehole wall. Along the radial direction, the reservoir temperature and pressure decrease exponentially with increasing distance from the wellbore. The radial variation range of the pressure field induced by steam injection is twice as wide as that of the temperature field, and both variation ranges decrease from the wellbore heel to the toe. This is because the reservoir pressure and heavy oil

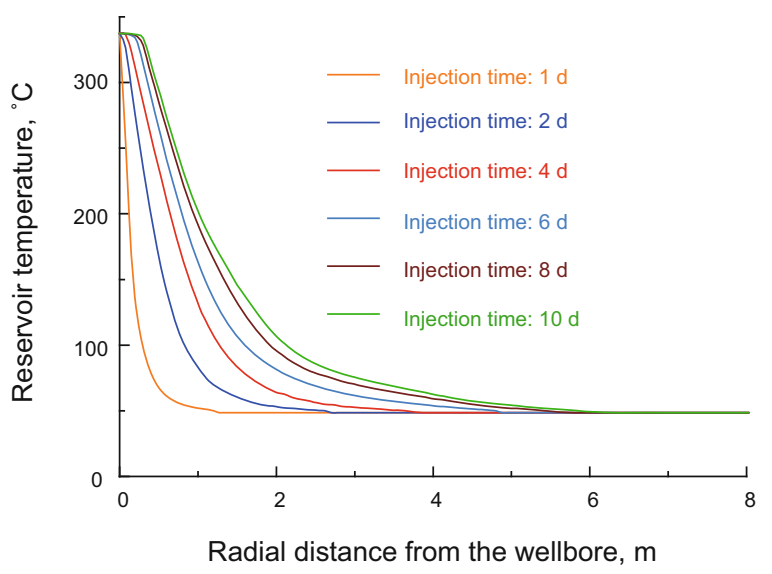

Fig. 6 Radial distribution curves of the reservoir temperature

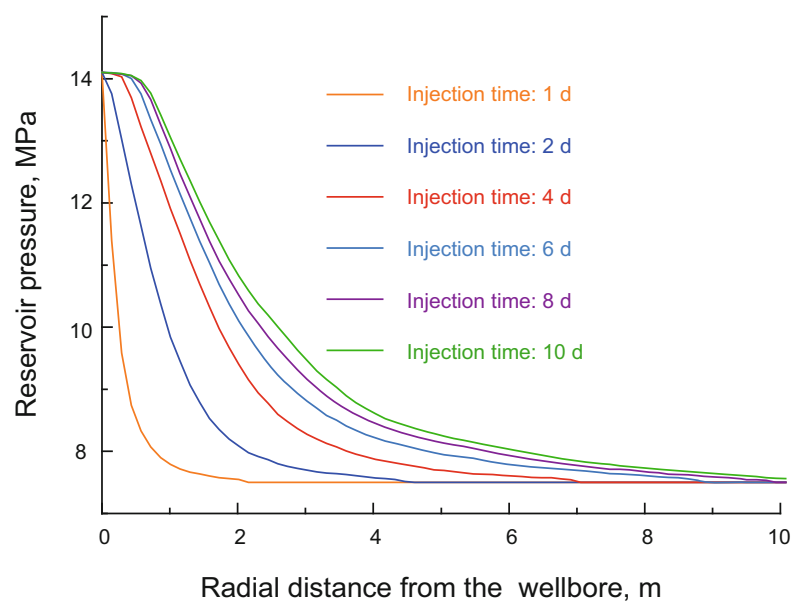

Fig. 7 Radial distribution curves of the reservoir pressure viscosity are both high under original reservoir conditions. This results indicate that only a small zone near the wellbore is heated by steam and the reservoir temperature and pressure decrease to their initial values at 2 and 4 meters from the borehole wall. The steam injected into the wellbore has a more significant influence on reservoir pressure than reservoir temperature, which is mainly caused by thermal convection (Sun et al, 2009). Steam absorption and internal energy decrease along the horizontal wellbore, so the radius of the steam-heated zone and the influence of steam on the reservoir pressure decrease with the distance from the wellbore heel. Fig. 5 shows that the water saturation in the vicinity of the wellbore decreases rapidly from about 1.0 to 0.4 (original value), exhibiting the same variation as the temperature and pressure fields, but the effect of steam on the water saturation is smaller than that on the reservoir temperature and pressure,

As shown in Figs. 6 and 7, the steam injection time has a significant effect on the reservoir pressure and temperature, and the radius of the heavy oil reservoir affected by steam varies from 1 to $5 \mathrm{~m}$ when the injection time ranges from 1 days to 10 days. However, the increment decreases gradually. This is because the temperature difference between steam and reservoir is high at the initial stage of steam injection, and the heat transfer rate (i.e., the quantity per unit time) is high, so the reservoir volume treated by steam increases significantly with steam injection time. After a period of steam injection, the temperature difference between the steam and the formation near the wellbore becomes low, so the rate of heat transfer from the steam to the formation reduces substantially and the rates of temperature and pressure changes diminish in the radial direction. Moreover, the increasing radius of the heated zone reduces the heat flow front energy, leading to a reduction in the effect of the injected steam.

\section{Conclusions}

1) A model is derived for calculating the dynamic temperature distribution in heavy oil reservoirs. By combining dynamic temperature distribution and pressure distribution equations for the reservoir and wellbore, a coupled thermohydro model is established. The model considers the coupling of temperature and pressure, and can be used to calculate three-dimensional dynamic temperature and pressure profile of reservoirs.

2) Only a small zone near the wellbore is affected by steam injection. The reservoir temperature and pressure decrease exponentially with increasing distance from the wellbore. Maximum values of the reservoir temperature and pressure appear at the borehole wall. The radial variation range of pressure field induced by steam is twice as wide as that of temperature field, while, from heel to toe, both variation ranges decrease along the horizontal well. Water saturation has the same variation as the temperature and pressure fields.

3) The steam injection time has a significant effect on the reservoir pressure and temperature, and the radius of the heavy oil reservoir affected by steam varies from 1 to $5 \mathrm{~m}$ when the steam injection time ranges from 1 days to 10 days. However, the increment decreases gradually. 


\section{References}

Bahonar M, Azaiez J and Chen Z. A semi-unsteady state wellbore steamwater flow model for prediction of sand face condition in steam injection wells. Canadian International Petroleum Conference, 16-18 June 2009, Calgary, Alberta, Canada

Chen Y M. Thermal Recovery by Steam Injection. Dongying: China University of Petroleum Press. 1996. 173-177 (in Chinese)

Cheng Q L, Liu Y, Wang Z G, et al. Coupled thermo-hydro analysis for wet saturated flow in porous media in an oil reservoir. Journal of Southwest Petroleum Institute. 2009. 30(9): 1451-1454 (in Chinese)

Hasan A R, Kabir C S and Wang X. A robust steady-state model for flowing-fluid temperature in complex wells. Paper SPE 109765 presented at SPE Annual Technical Conference and Exhibition, 1114 November 2007, Anaheim, California

Huang S J, Cheng L S, Zhao F L, et al. Production evaluation model of a fishbone well considering coupling among multi-segment flows. Journal of China University of Petroleum (Edition of Natural Science). 2010. 34(2): 83-88 (in Chinese)

Izgec B, Kabir C S, Zhu D, et al. Transient fluid and heat flow modeling in coupled wellbore/reservoir systems. Paper SPE 102070 presented at SPE Annual Technical Conference and Exhibition, 24-27 September 2006, San Antonio, Texas, USA

Liu H Q, Zhang H L and Wang P X. Interpretation of temperature profiles during soak periods in steam-stimulated wells. Petroleum Science. 2007. 4(4): 74-79

Liu X P, Guo C Z, Jiang Z X, et al. A model coupling fluid flow in the reservoir with flow in the horizontal wellbore. Acta Petrolei Sinica. 1999. 20(3): 82-86 (in Chinese)

Livescu S, Drulofsky L J and Aziz K. A semianalytical thermal multiphase wellbore-flow model for use in reservoir simulation. Paper SPE 115796 presented at SPE Annual Technical Conference and Exhibition, 21-24 September 2008, Denver, Colorado, USA

Livescu S, Durlofsky L J, Aziz K, et al. Application of a new fullycoupled thermal multiphase wellbore flow model. Paper SPE 113215 presented at SPE/DOE Improved Oil Recovery Symposium, 19-23 April 2008, Tulsa, Oklahoma, USA

Ouyang L B and Azizk H. A general single-phase wellbore/reservoir coupling model for multilateral wells. SPE Reservoir Evaluation \& Engineering. 2001. 4(4): 327-335 (paper SPE 72467)

Su Y L, Zhang D and Li M Z. A mathematical model coupling seepage in the reservoir with flow in the horizontal wellbore. Journal of China University of Mining \& Technology. 2007. 36(6): $752-757$ (in Chinese)

Sun B G, Gai P Y and Liu H Q. A calculation model of threedimensional static temperature profile for steam huff and puff in a horizontal well. Fault-Block Oil \& Gas Field. 2010. 17(5): 566-570 (in Chinese)

Sun F, Xue S F and Tong X H. A coupled T-H-M model with applications to steam injection in heavy oil reservoirs. Chinese Journal of Underground Space and Engineering. 2009. 5(5): 924-927 (in Chinese)

Walters D A, Settari A and Kry P R. Coupled geomechanical and reservoir modeling investigating poroelastic effects of cyclic steam stimulation in the Cold Lake Reservoir. SPE Reservoir Evaluation \& Engineering. 2002. 5(6): 507-516 (paper SPE 80997)

Wang B X. Convective heat and mass transfer in porous media. Journal of Xi'an Jiaotong University. 1994. 28(5): 51-56 (in Chinese)

Wang Y P, Li M Z, GAO X, et al. A new parameter calculating model for steam flooding in a horizontal wellbore. Journal of Southwest Petroleum University (Science \& Technology Edition). 2010. 32(4): 127-132 (in Chinese)

Wu S H, Yu L J, Liu X E, et al. Thermal recovery numerical simulation coupling flow in reservoir with various-mass-rate flow in horizontal wellbore. Petroleum Exploration and Development. 2004. 31(1): 8890 (in Chinese)

Yin S D, Dusseault M B and Rothenburg L. Fully coupled numerical modeling of ground surface uplift in steam injection. Journal of Canadian Petroleum Technology. 2010. 49(1):16-21 (paper SPE 132755)

Zandi S, Renard G, Nauroy J F, et al. Numerical modeling of geomechanical effects during steam injection in SAGD heavy oil recovery. Paper SPE 129250 presented at EOR Conference at Oil and Gas West Asia, 11-13 April 2010a, Muscat, Oman

Zandi S, Renard G, Nauroy J F, et al. Numerical coupling of geomechanics and fluid flow during steam injection in SAGD. Paper SPE 129739 presented at SPE Improved Oil Recovery Symposium, 24-28 April 2010b, Tulsa, Oklahoma, USA

Zhou S T and Guo X X. Study of coupling flow in perforated horizontal wells with reservoir flow. Petroleum Drilling Techniques. 2009. 37(4): 84-87 (in Chinese)

(Edited by Sun Yanhua) 